\title{
Hidden Facts and the Role of Truthfulness in Academic Dishonesty
}

Pius Musau

PhD candidate, Medical Education

Moi University, School of Medicine, Department of Surgery and Anaesthesiology

Email: musau_pius@yahoo.com

Background: Academic dishonesty is widespread across the world and studies done have largely relied on self-reporting to establish the extent and factors contributing to the practice. This demands of researchers to take at face value what people who may not be entirely truthful are saying. It is not a surprise, therefore, that varied interesting findings have been made in different studies. This paper delves into the complexity of determining the key components of academic dishonesty and brings into focus the role of truthfulness in understanding the elicited data. The objective of this study was to establish the role of truthfulness in understanding various components of academic dishonesty.

Methods: This was a Cross sectional study using self-administered questionnaire. The Setting was the School of Medicine, Moi University, Eldoret - Kenya. The study subjects were 156 students in the clinical $\left(4^{\text {th }}, 5^{\text {th }}\right.$ and $\sigma^{\text {th }}$ ) years of study. They anonymously filled a 20-item self-administered questionnaire. The questionnaire captured the demographic data and the views of the students on various aspects of academic dishonesty ranked in a Likert scale of six levels starting with strongly agree to strongly disagree.

Results: The overall level of truthfulness among these medical students was $55.8 \%$. While more males had prior experience with academic dishonesty in secondary school and involvement at College, they were also more truthful than the females. The untruthful were 2.2 times as often involved in academic dishonesty as the truthful and were also less likely to report on their classmates.

Conclusion: There are hidden facts in academic dishonesty that can only be revealed by subjecting gathered data to a scrutiny on how truthful the respondents are. Truthfulness is an inversely proportional surrogate predictor of academic dishonesty.

Key words: Role. Thruthfulness, academic, dishonesty

DOI: http://dx.doi.org/10.4314/ecajs.v21i3.25

Introduction

Academic dishonesty is rampant across geographical regions ${ }^{1,2}$ and there is concern that it is rapidly rising due to technological advancement ${ }^{3}$. With prevalence between $13 \%$ and $95 \%$ (1), academic dishonesty is an elusive practice with hidden facts not readily discernible. No one is immune from this vice and those in institutions rife with it may be involved to either not be disadvantaged or to fit in the system ${ }^{4}$. It sounds a contradiction in terms to evaluate academic dishonesty by relying on data that may not be wholly truthful given the nature of the source. This paper explores the hidden facts on academic dishonesty and establishes the role of truthfulness in understanding various aspects of the malpractice.

\section{Subjects and Methods}

Medical students in the clinical $\left(4^{\text {th }}, 5^{\text {th }}\right.$ and $\left.6^{\text {th }}\right)$ years of study anonymously filled a 20 -item self-administered questionnaire. The questionnaire captured the demographic data and the views of the students on various aspects of academic dishonesty ranked in a Likert scale of six levels starting with strongly agree to strongly disagree. Collected data was transcribed into a sheet and entered for analysis using Statistical Package for Social Sciences (SPSS) version 21. The truthfulness of the students' information was adjudged on the basis of consistency in answering questions derived from preceding answers. Subjective data was presented in frequencies while measures of dispersion and central tendencies with statistical significance at $\mathrm{p} \leq 0.05$ were applied on discrete data. The results are presented in narratives, ratios and percentages.

\section{Results}

One hundred and fifty-six students responded to the self-administered questionnaire. The male to female ratio was 1.3:1 and the age ranged from 21 to 34 years with a mean \pm standard deviation of $24.1 \pm 1.8$ years. Academic dishonesty was defined as any form of misconduct that gives undeserved advantage to the concerned student in a formal academic exercise by $98.7 \%$ of the students. A total of 27 students $(17.3 \%)$ had participated in academic dishonesty while in secondary schools. Males were 3.2 times as likely to have been exposed to academic dishonesty as the females $(\mathrm{p}=0.002)$. A total of $80 \%$ of the respondents were aware of academic dishonesty, $75.6 \%$ had witnessed it in progress while $60.9 \%$ confessed to having participated at least once. 


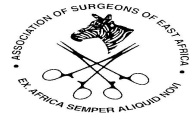

Majority of those involved were males (55\%). Of those who took part in academic dishonesty, $72.6 \%$ believed that their classmates too were involved in the activity.

The overall level of truthfulness among these medical students was 55.8\%. The males were more truthful than the females $(59.8 \%$ vs. $50.7 \%)$. Two thirds of the $6^{\text {th }}$ year of study were truthful while the other two years barely passed the $50 \%$ mark respectively. Bigger proportions of the untruthful claimed not to have participated in academic dishonesty while in secondary school $(85.5 \%$ vs. $80.5 \%)$ and to be aware of cheating in College $(81.2 \%$ vs. $79.3 \%)$ respectively. Three quarters of each group had witnessed academic dishonesty in progress but the untruthful were 2.2 times as often involved in academic dishonesty as the truthful lot $(\mathrm{p}=<0.001)$. The truthful were 1.4 times as often as the untruthful in believing that their classmates were involved in academic dishonesty.

\section{Discussion}

Studies done on academic dishonesty have all along been counting on the honesty and truthfulness of the respondents while at the same time exploring on a vice acknowledged to be complex and widespread ${ }^{1-4}$. We now have a situation where students consider dishonesty as a way of life "because everybody does it" ${ }^{5,6}$. With academic dishonesty morphing into sophisticated forms due to advancement in technology ${ }^{7}$ it is plausible that we have not been having the complete picture of the monster. This informed the objective of this paper that set out to unearth the hidden facts and establish the role of truth in understanding academic dishonesty.

The socialization has been to acknowledge academic dishonesty as more common in some and not other courses $^{8}$. The presumption would be that some noble courses like Medicine and Engineering that deal with matters of life and death would be free of the finding that only 55.8\% of medical students are truthful; just slightly better than tossing a coin on whom to believe! One would be tempted to augment this finding with the fact that the participation level of $60.9 \%$ is perfectly within study findings of a range $13-95 \%$ for the others ${ }^{1}$ and made more colourful by an awareness of $80 \%$ and witnessing of the vice in progress at $75.6 \%$. It is possible that the trends on academic dishonesty are no respecters of any given profession and this might explain why we are increasingly getting litigations aimed at respected professions like Medicine and Architecture ${ }^{9,10}$.

The demography of academic dishonesty has been noted to change from study to study probably because of the failure to factor in consistency and hence truthfulness of the respondents. While MacCabe and colleagues ${ }^{1}$ as well as Buckley et al ${ }^{11}$ found males to be involved more, Leming ${ }^{12}$ found that under a low-risk condition, females cheated more than males and that a higher risk of punishment deterred females but not males. This study established that women are less truthful than men and it is possible the higher numbers for men could be due to a greater level of honesty in their reporting. It is also thought that in a paternalistic masculine society, females would find it more difficult to disclose on their part the bad trait of dishonesty that may be considered a necessity for the very survival of the competitive macho male and less so for the female ${ }^{12}$.

Older students $\left(6^{\text {th }}\right.$ years $)$ were found to be not only more truthful but also less involved in academic dishonesty when compared to the younger ones. This is in keeping with findings by other studies that females, older students and higher academic endowment were associated with lesser likelihood of involvement 1, 2, 11, 13. Truthfulness can, based on this study's findings, be a surrogate predictor of involvement in an inverse proportion manner and fits well with the finding that the untruthful were 2.2 times as likely to be involved in academic dishonesty as the truthful students.

Of interest is the finding that both groups will have equal chances of witnessing an event like cheating in progress but the truthful will have higher scores on disclosing the involvement of classmates in academic dishonesty. It might suggest that the bigger number of the untruthful who say they were not involved in academic dishonesty in secondary school and that they are aware of cheating in the College are rationalizing and engaging in self-cleansing by creating a scenario where they not only absolve themselves but also drag in the rest in the collective guilt of dishonesty. This can be affirmed by similar finding by Williams and Hosek who asserted that even dishonest students are rational and disclose things based on their evaluation of best responses pertaining to internal and external influences ${ }^{14 .}$

\section{Conclusion}

There are hidden facts in academic dishonesty that can only be revealed by subjecting gathered data to a scrutiny on how truthful the respondents are. Truthfulness is an inversely proportional surrogate predictor of academic dishonesty. 
Recommendation

A paradigm shift is advised in further studies on academic dishonesty with greater focus on reliability of information gathered on the malpractice.

\section{Acknowledgement}

I wish to acknowledge the great input by the respondents without which this paper would not have been realized.

References

1. McCabe, D. L., Butterfield K. D., Trevino L. K. Academic Dishonesty in Graduate Business Programs: Prevalence, Causes, and Proposed Action. Academy of Management Learning \& Education 2006; 5(3): 294-305

2. Park, C. In Other (People's) Words: Plagiarism by University Students-Literature and Lessons. Assessment \& Evaluation in Higher Education 2003; 28: 471-488.

3. Born, A. D. How to Reduce Plagiarism Journal of Information Systems Education 2003; 14: 223.

4. Sattler, S., Graeff, P., Willen, S. Explaining the Decision to Plagiarize: An Empirical Test of the Interplay between Rationality, Norms, and Opportunity. Deviant Behavior 2013; 34: 444-463

5. Davis, S.F., Grover, C.A., Becker, A.H., McGregor, L.N. Academic dishonesty: prevalence, determinants, techniques, and punishments. Teaching of Psychology 1992; 19(1): 16-20.

6. DiBartolo, M. C., Walsh, C. M. Desperate times call for desperate measures: Where are we in addressing academic dishonesty? Journal of Nursing Education, 2010 49(10), 543-544.

7. McCabe, D.L, Trevino, L.K, Butterfield D.L. Honor Code and Other Contextual Influences on Academic Integrity: A Replication and Extension to Modified Honor Code Settings. Research in Higher Education 2002; 43(3):368.

8. Bachore, M. M. Academic Dishonesty/ Corruption in the Period of Technology: Its implication for Quality of Education.American Journal of Educational Research 2014; 2(11):1060-1064.

9. Akaranga, S.I .,Ongong , J.J. The phenomenon of Examination Malpractice: An Example of Nairobi and Kenyatta Universities. Journal of Education and Practice 2013; 4(18): 87-96.

10. Gudo, C.O, Olel, M.A, Oanda, I.O. Students' Admission Policies for Quality Assurance: Towards Quality Education in Kenyan Universities. International Journal of Business and Social Science 2011; 2(8): $177-183$

11. Buckley, M. R., Wiese D. S., Harvey M. G. An Investigation Into the Dimensions of Unethical Behavior . Journal of Education for Business, 1998; 73(5): 284-290.

12. Leming, J. S. Cheating Behavior, Subject Variables, and Components of the Internal-External Scale Under High and Low Risk Conditions. Journal of Educational Research, 1980;74(2): 83-87.

13. Bushway,A., Nash W.R . School Cheating Behavior. Review of Educational Research 1997;47(4): 623

14. Williams, M. S., Hosek W. R. Strategies for Reducing Academic Dishonesty. Journal of Legal Studies Education 2003; $21: 87$. 